\title{
Revitalización del eje fluvial Río Claro de Talca como potencial turístico de la Región del Maule
}

Revitalization of the Claro fluvial axis of Talca as a tourist potential of the Region of Maule

\author{
Camila Alarcón* \\ Simón Díaz
}

Resumen: El presente trabajo tiene como objetivo la creación de una política pública para revitalizar el eje fluvial Río Claro en la comuna de Talca, incorporando a los ríos Piduco y Lircay. Este río dentro de la ciudad corresponde a su principal balneario, y donde los talquinos ven con preocupación la falta de inversión en el lugar, a nivel de servicios, seguridad y recreación. La política pública a implementar debiera tener una serie de pasos definidos en su organización y sustentada a partir del trabajo entre distintos actores como son gobierno, empresarios locales y ciudadanía, involucrándolos en su participación para la reactivación de este pulmón verde y proyectándolo como el principal centro fluvial de la región, y donde además se conectará la capital regional con las comunas de Río Claro y Maule a través del río, lo cual generará múltiples beneficios socio económicos para la comunidad.

Palabras clave: Río Claro, eje fluvial, políticas públicas, Talca, Maule.

\begin{abstract}
This work aims to create a public policy to revitalize the Rio Claro river axis in the commune of Talca, incorporating the Piduco and Lircay rivers. This river within the city corresponds to its main spa, and where the talquinos they are concerned about the lack of investment in the place, at the level of services, security and recreation. Public policy to be implemented will have a series of steps defined in your organization and supported from the work between different actors such as government, local entrepreneurs and citizens, involving them in their participation in the reactivation of this green lung and projecting it as the main river center of the region, and where the regional capital will also connect with the communes of Río Claro and Maule through the river, which will generate multiple socio economic benefits for the community.
\end{abstract}

Keywords: Rio Claro, river axis, public policies,Talca, Maule.

Recibido: 19 octubre 2020 Aceptado: 6 diciembre 2020

\section{Introducción: la vocación fluvial de Talca}

La ciudad de Talca, fundada hace 278 años y capital regional del Maule, es tierra de grandes hitos y hazañas nacionales, desde el acta de Independencia firmado el 12 de febrero de 1818, pasando por

\footnotetext{
*Universidad Autónoma de Chile, Magister en Gestión Municipal, camila.alarcon.nunez@gmail.com

** Universidad Autónoma de Chile, Magister en Gestión Municipal, simon.hdm@gmail.com
} 
acontecimientos también históricos como la Batalla de Lircay de 1830 a orillas del mismo río. También es tierra de la conocida frase "Talca, París y Londres", haciendo honor a su gran crecimiento industrial de principios del siglo XX, además de tener desde el siglo XVIII navegación entre el puerto de Nueva Bilbao (actual Constitución) por el Río Maule, hasta las cercanías en la zona sur de Talca.

La ciudad de Talca, además, es tierra de características particulares y singulares, posee un clima templado mediterráneo, ideal para la industria del vino y agricultura frutícola, manzanas, tomate, nueces, entre tantas otras. Talca es parte de una microcuenca, la cual posee una gran cantidad de cerros que son la entrada a la cordillera de la costa y mirándonos desde lo alto en una de sus cumbres la tradicional "virgen del cerro". Dentro de este medio geográfico, Talca posee en el sur y el norte barreras naturales de gran valor patrimonial y cultural. Estos son los ríos Piduco en el sur y Lircay por el norte y que desembocan en el gran río de la ciudad que es el Claro, incluso este río es parte de la historia e identidad local y donde el historiador Sánchez (2012) señala que "fue en esta región, con más precisión en las riberas del río Claro, afluente norte del Maule, donde los Incas levantaron un fuerte" (pág. 22). En otras palabras, el río no solo es parte de la identidad actual de la ciudad, sino que además es un punto de encuentro entre los indígenas que compartieron con la civilización inca en esta zona.

Dicho lo anterior, Talca es bastante rica, desde lo cultural y natural, dotada de atractivos que en algunos casos podrían ser mayor explotados, siempre pensando en beneficio de la comunidad. Es por ello, y considerando el enorme sello de identidad local e historia que poseen algunos puntos de la ciudad es que, en este estudio, se buscará potenciar y revitalizar el principal eje fluvial de la comuna, como es Río Claro, siendo este, el principal balneario desde principios del siglo XX, fomentando, además, la reactivación del transporte acuático por los ríos Piduco y Lircay. En el texto "turismo urbano y la geografía de la ciudad", el autor señala la importancia de utilizar estos espacios de área verde para la comunidad:

Tales áreas pueden ser atractivas precisamente porque no han sido construidas ni dispuestas para los turistas. Afuera de la habitual zona cómoda, los turistas pueden pasear en un espacio intelectual y físico interesante e impredecible. (Judd, 2003, pág. 57)

Considerando lo anterior, durante muchas administraciones municipales, el Río Claro siempre ha sido prioridad para lograr en este espacio, un punto de encuentro entre los ciudadanos, pero donde la realidad de este lugar a partir del año 2000, ha sido deplorable. El río Claro, durante un tiempo se ha convertido en un basurero clandestino, lugar de carreras ilegales de auto y zona para la ingesta ilegal de alcohol y otras sustancias.

Dado estos antecedentes, pretendemos recuperar este espacio y potenciarlo, a fin de lograr en él, un centro fluvial de grandes características y transformarlo en el principal atractivo turístico de la zona, reconociendo, además, la geografía e identidad regional a la hora de potenciar un recurso natural y su alcance social. Sobre ello, Judd (2003) argumento que:

Los ambientes habitados por los visitantes de las ciudades recorren todo el espectro, desde los espacios construidos específicamente para la producción del espectáculo y el consumo, hasta espacios públicos como frentes de agua, parques y plazas, pasando por comercios y calles residenciales. Esta compleja geografía proporciona muchas oportunidades a los visitantes para escapar de los confines del encierro. Judd, 2003, pág. 56)

De acuerdo a lo señalo por Judd, se considera que cada espacio geográfico presenta características únicas y las cuales deben ser aprovechadas a través de un buen trabajo y planificación de los espacios para la recreación y que deben ser pensados desde la identidad regional. Sobre este asunto, Valenzuela argumenta en cuanto a la identidad y planificación que "es la historia de lucha de las regiones por la 
autonomía territorial versus la implacable maquinaria represivo-cooptadora del centralismo chileno" (Valenzuela 2017: 73). Dicho esto, se pretende realizar una política pública a partir de las particularidades de este lugar del país. Complementaria a esta idea, Cal (2002) en "Ríos y ciudades: aportaciones para la recuperación de los ríos y riberas de Zaragoza" sostiene lo siguiente: "Uno de los tópicos más frecuentes al hablar de «fachadas fluviales» es el que señala que determinadas ciudades «dan la espalda» a sus ríos, por lo que resulta necesario invertir la situación”. (Cal, 2002, pág. 16)

De acuerdo a la noción del autor, esta tarea de recuperación de los ríos y no "darle la espalda", se complementa a partir del anhelo de la municipalidad y la idea de transformar a Talca en una de las ciudades con mayor cantidad de áreas verdes por habitante, esto a partir de la intervención de diferentes sectores de la ciudad y donde el eje fluvial Río Claro es la gran obra a realizar con más de 10 hectáreas de recuperación del borde del río. Además de acuerdo a lo señalado por el Ministerio de Vivienda, MINVU en 2019, este parque beneficiará a más de 200 mil personas que habitan la ciudad de Talca. Incluso se busca que la comuna pueda obtener 9 metros cuadrados de área verde por habitante hacia finales del 2020 de acuerdo a lo declarado por el actual alcalde en entrevista con un medio local (TV Maule).

De acuerdo a lo señalado, es que se llevará a cabo una política pública multiactor pudiendo incorporar distintos comercios y servicios en beneficio de la ciudadanía y también a favor de la economía local, fomentando el turismo principalmente. Sumado a lo anterior, se realizará un trabajo sistémico entre municipios en los cuales pasa el Río Claro, creando una red de turismo acuático entre las comunas de Río Claro, Talca y Maule, fomentando el transporte acuático y transformando al río en un verdadero centro de identidad regional. Sumado a ello, dentro de este trabajo, se considerarán buenos ejemplos de conservación y planificación territorial de borde de ríos a nivel internacional y local, lo cual es importante a la hora de repensar un buen proyecto a partir de las condiciones geográficas y sociales que posee la ciudad de Talca y sus habitantes. Incluso en el libro Agua y patrimonio en la Región del Maule: una mirada desde la historia, se señala en relación a la importancia del río lo siguiente:

El río Claro se asocia indefectiblemente al desarrollo de la ciudad, ya que aparece referido como un punto importante en su acta de fundación, ya que desembocan en él sus dos esteros emblemáticos: Piduco y La Chimba o Baeza. Constituyéndose, durante el siglo XIX, en una vía de transporte de la producción de siete molinos existentes en la ciudad. Desde el puerto fluvial de Perales hasta la confluencia con el Maule. (Simón \& Sánchez, 2015, pág. 83)

Considerando la importancia histórica del Río Claro para los habitantes de Talca, es que revitalizar este eje a partir de una pública logrará entregar servicios a la comunidad en el parque fluvial. Además, se creará una red ordenada de comercio en el lugar trabajando con actores empresarios locales. Por último, se creará un organismo de transporte acuático local, fomentando el transporte fluvial por el Río Piduco y Lircay y que llega al Río Claro, siendo una forma de descongestión de las calles.

Finalmente, a partir del trabajo de estos actores, la comunidad de Talca podrá disfrutar de un espacio cómodo, con servicios varios y además fomentando el turismo.

\section{Reseña histórica del Río Claro}

Con una extensión de 42 kilómetros de largo, el Rio Claro ubicado en la región del Maule, se constituye como una de las fuentes hídricas más relevante de la zona. En su recorrido atraviesa por las comunas de Molina, Río Claro, Sagrada Familia, San Rafael y Talca, siendo el principal atractivo turístico de esta última. 
Surge en la cordillera de los Andes en el paso Malacara, en el sector alto del Parque Inglés perteneciente a la Reserva Nacional Radal Siete Tazas en la provincia de Curicó. En sus inicios se presenta como un río dendrítico, es decir cuenta con múltiples ramificaciones dominadas por el volcán Descabezado Grande. En su nacimiento el rio se encajona entre paredes de roca de origen volcánico. Estas murallas pueden alcanzar alturas de hasta 25 metros, formando también diferentes pozones de aguas cristalinas. Posteriormente corre paralelo al rio Lontué, (afluente del Mataquito) y del cual solo se separa por $8 \mathrm{Km}$. Desde su formación el rio Claro se dirige hacia el noroeste para luego doblar hacia el sur en dirección a la ciudad Talca, formando una especie de "v" invertida. Sobre esta situación, la Dirección General de Aguas señala lo siguiente: "Una notable característica de la trayectoria de este río es su brusco cambio de rumbo en las proximidades de Molina, variando en $90^{\circ}$ hacia el SW, rumbo que conserva hasta su junta al Maule, bordeando el pie oriental de la cordillera de la Costa. En esta trayectoria recoge afluentes importantes, como el estero Pangue y el río Lircay" (DGA 2004, p. 63).

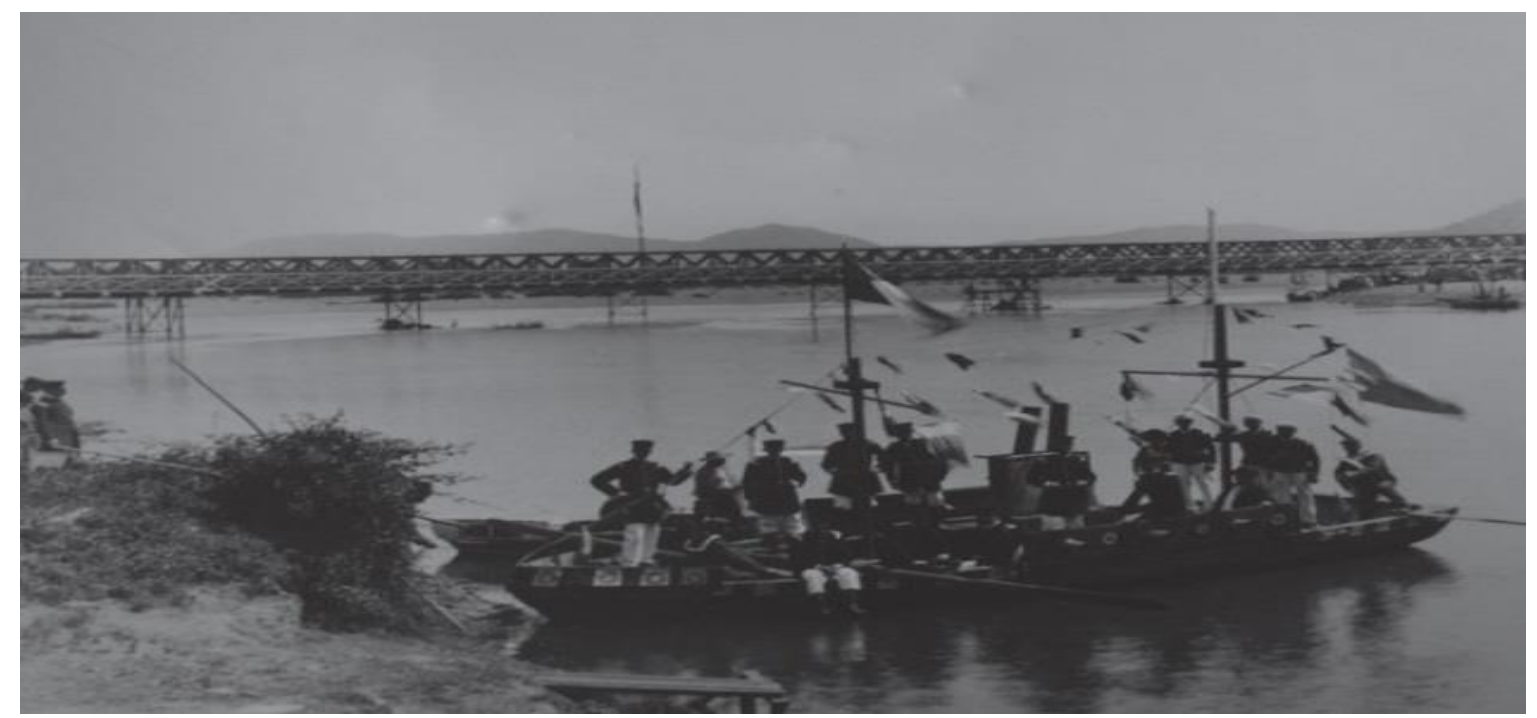

Fotografía bomberos en el río Claro en 1923. Autor Fortunato Rojas (imagen extraída de desde Agua y Patrimonio en la R. del Maule, 2015)

Durante su recorrido por las diferentes comunas por las cuales atraviesa, este afluente pierde su claridad y cuenta con un precario mantenimiento y muy poca higiene, ya que por sus riveras cuenta en diferentes lugares con micro basurales e incluso vertederos de escombros, los cuales en invierno y con las lluvias, al crecer el río, arrastran todo este material contribuyendo a la contaminación de las aguas. (Baltanares y Figueroa 2018) Sin embargo, es en la ciudad de Talca, específicamente en el Balneario río Claro, en donde el cauce se encuentra medianamente cuidado por ser el principal atractivo turístico de la zona y el más tradicional, ya que en sus inicios era apto para el baño, no obstante, en la actualidad por su alta contaminación, solo cuenta con embarcaciones para paseo fluvial y actividades recreativas que se realizan en su rivera.

Finalmente, llega a su punto de confluencia en donde el Claro se junta con las aguas del rio Maule, en el lugar conocido como Linares de Perales. Este punto es el lugar exacto en el los faluchos maulinos culminaban su navegación proveniente desde el puerto Nueva Bilbao (Constitución), embarcaciones de carácter liviano, que a finales del siglo XIX hasta el siglo XX, transportaban por el Maule la producción local de madera, trigo, cereales y vino, hasta lugares como Perú y California. 
Manuel Almagro, uno de los especialistas de la Comisión Científica del Pacífico de 1862- 1866, comentaba sobre Chile que "este país exportaba principalmente cereales para todo el Pacífico y Oceanía, además de vinos y caballos finos para las repúblicas de más al norte. Así, junto al movimiento de barcos de mayor calado, con destino a la costa del Perú y Bolivia, iban las lanchas y faluchos maulinos cargados de productos locales (vinos, quesos, cerdos, madera, etc.), o en su defecto, llevaban carbón de Lota (Maino 1996, p. 63).

Lo mencionado anteriormente, explica la importancia del río Maule a fines del siglo XIX y principios del siglo XX, en el auge económico que experimento la zona, no obstante, el río Claro, aunque no se utilizó para el transporte ni navegación de los famosos faluchos, ha cumplido un rol fundamental por su alto valor ambiental, así como también turístico para la zona en la cual se encuentra emplazado. Tomando en consideración que un río es un elemento natural que construye paisaje, el Claro es una fuente importante de agua para la agricultura de la región, además de encargarse de transportar elementos bióticos, así como también aquellos que provienen de la contaminación y el mal uso de las aguas del cauce.

\section{Características territoriales de las comunas donde se aplicará la política pública}

Para este trabajo, se consideran las características regionales de las ciudades por las cuales pasa el río Claro, debido a que se pretende instaurar una red fluvial en este curso de agua, participando en esta red las comunas de Río Claro, Talca y Maule. Cabe destacar que esta región tiene 30 comunas en sus cuatro provincias, y donde más del $57,1 \%$ de su población está asentada en la provincia de Talca de acuerdo la información que posee la Gobernación de la provincia de Talca (2020). Dicho esto, las 3 comunas que se presentan a continuación son parte de esta provincia.

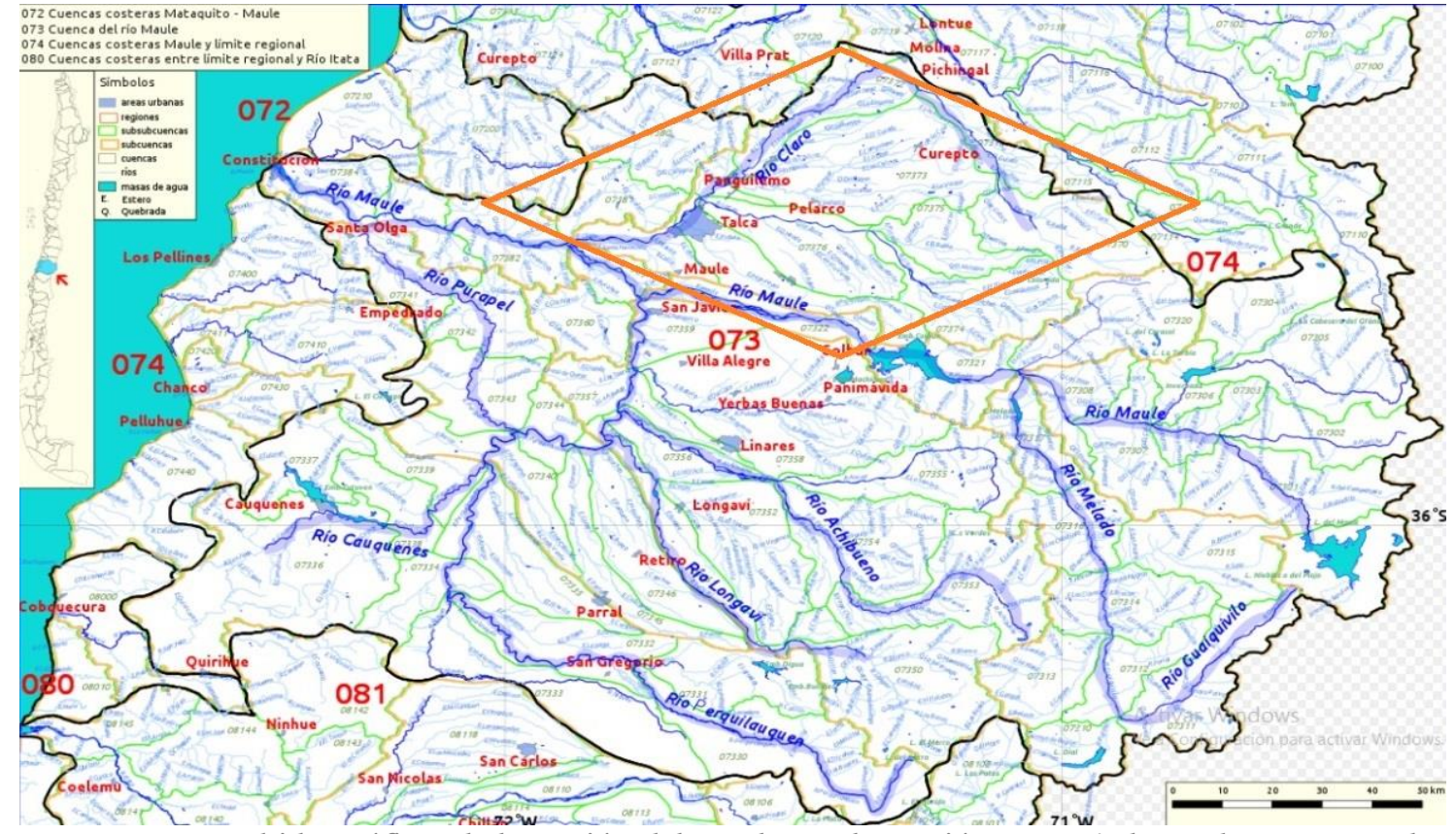

Mapa cuencas hidrográficas de la Región del Maule. En la sección anaranjada se observa zona de confluencia del río Claro con las comunas de Talca, Maule y Río Claro (Red hidrográfica desde BCN, 2019). 


\section{Comuna de Río Claro}

Fundada en mayo de 1899. Esta comuna chilena se encuentra en plena depresión intermedia. Cuenta con una superficie $431 \mathrm{Km} 2$ y una población de 13.906 habitantes de acuerdo a los datos aportados por el Censo 2017 (INE, 2017). Rio Claro recibe su nombre en honor al río del mismo nombre y que atraviesa la comuna, siendo este curso de agua vital en la industria agrícola de la zona, principalmente ligada al tabaco, nueces y manzanas. Vale decir que esta comuna se ubica a unos $40 \mathrm{~km}$ de la ciudad de Talca y donde a partir del río Claro, se pretende conectar a través de una vía de comunicación fluvial.

\section{Comuna de Talca}

Fundada en 1692 por el gobernador español Tomás Marín de Poveda en la zona donde actualmente se ubica la comuna de Maule. Recién en 1742, fue refundada en su actual ubicación por el también gobernador José Manso de Velasco. La ciudad de Talca al día de hoy, es la capital regional del Maule, concentrando la mayoría de los servicios requeridos por la comunidad regional. En cuanto a sus características, cuenta con una superficie de $232 \mathrm{Km} 2$ y una población de 220.357 de acuerdo a los datos aportados por el Censo 2017 (INE, 2017). La ciudad es parte de una microcuenca situada en el límite de la depresión intermedia con la cordillera de la costa y donde en este punto de convergencia se sitúa el principal eje fluvial de la comuna, siendo este el río Claro, el cual además es alimentado por otros ríos importantes de la ciudad como son el Piduco por el sur y el Lircay por el norte. Dadas estas últimas características, pretendemos revitalizar el borde del río Claro, fomentando su uso en el parque situado en su rivera, siendo este el único balneario de la comuna y que también será parte de una red fluvial de transporte con las comunas de Río Claro en el norte y Maule en el sur.

\section{Comuna de Maule}

Fundada en diciembre de 1927, esta comuna se encuentra actualmente conurbada en su límite norte con la ciudad de Talca. Al igual que la capital regional, esta ciudad se encuentra en el límite entre la depresión intermedia y la cordillera de la costa, siendo atravesada por el río Claro en su límite Este. Vale mencionar que el río Claro en esta comuna desemboca en el río Maule, el principal curso de agua regional y que dentro de la historia de este lugar fue el límite entre los diferentes pueblos indígenas que habitaron la zona, destacando a los incas y mapuches. Finalmente, Maule, posee una superficie de 238 $\mathrm{Km} 2$ y una población de 49.721 habitantes de acuerdo a los datos aportados por el Censo 2017 (INE, 2017).

\section{Política pública para eje fluvial río claro}

El lema de la política pública debiera ser la revitalización del eje fluvial río Claro no solo tiene su alcance en la ciudad de Talca, sino que, además, incorpora a las comunas de Río Claro y Maule. Considerando esta situación, se presenta el siguiente lema "El Maule mucho más Claro".

Chile es un país rico en recursos hídricos, atravesando su territorio una gran cantidad de ríos desde lo alto de la Cordillera de los Andes hasta finalmente desembocar en el Océano Pacífico. Si bien, desde la zona centro hacia el extremo sur, se cuenta con un gran número de ríos, existe una realidad en algunos puntos del territorio, donde hay una escasa preocupación de su mantenimiento, ya sea detectando vertederos ilegales o también fiscalizando el correcto uso de sus aguas. Dicho esto, a nivel regional y como forma de potenciar el principal balneario de Talca, que es la ciudad más grande, se busca 
revitalizar el eje río Claro, favoreciendo a la comunidad, dando solución a diferentes necesidades como son mayores espacios recreativos y también, favoreciendo el empleo a partir de la incorporación de comercio formal a esta zona de la ciudad.

Para transformar al eje fluvial rio Claro en uno de los grandes puntos de encuentro y turismo dentro de la región del Maule, se deben considerar las características geográficas en donde se implementará la red acuática de transporte y también, el comercio y servicios para la comunidad y estará ubicado en el parque que se encuentra en la ribera del río. Sin duda, esta política pública de revitalización del eje fluvial río Claro, afecta de manera positiva a todo el entorno de la ciudad de Talca y las comunas que serán parte del circuito acuático como son Río Claro por el norte y Maule en el sur, lo cual, a su vez, podría generar números positivos en la industria del turismo y servicios de la zona. Si consideramos que actualmente la región del Maule es una de puntos del país que concentra mayores niveles de pobreza, la política pública a implementar podría traer grandes beneficios aprovechando el recurso hídrico río Claro. Incluso, el académico Valenzuela (2017) destaca sobre estos niveles de pobreza lo siguiente:

Diez regiones en diversos indicadores tienen mayores niveles de pobreza: siete del centro sur (en especial Maule y Araucanía) y tres del norte (Arica, Atacama y Coquimbo). Tal como la geografía de Chile es diferente, sus regiones muestran niveles de desarrollo desiguales. Sus aportes en economía, cultura, educación, trabajo, e igualmente los índices de pobreza difieren según los territorios (Valenzuela, 2017, pág. 39).

De lo expuesto anteriormente, se considera la importancia de reconocer que cada zona del país presenta características distintas en cuanto a su identidad. Sobre esta situación, el académico Thayer (2011) complementa esta noción a partir de que "en efecto si asumimos que las identidades colectivas no son cuerpos estáticos sino históricos, y si aceptamos además que el reconocimiento es una dinámica social con entidad formativa de identidades" (Thayer 2011, pág. 271). Es por ello qué, se buscará potenciar el eje fluvial de la capital del Maule y conectarlo con otras comunas, reconociendo la identidad de este centro hídrico con cada uno de estos asentamientos urbanos desde hace ya más de 100 años.

Finalmente, en cuanto a los actores que participaran en esta política pública, es vital su trabajo, destacando organismos de gobierno como son los municipios, Gobierno Regional y ministerios afines. Finalmente, en el área privada, se incorporarán asociaciones de transporte acuático de los ríos, comerciantes locales, entre otros. El objetivo general es revitalizar el eje fluvial Río Claro de la comuna de Talca, proyectándolo como el principal atractivo turístico de la zona.

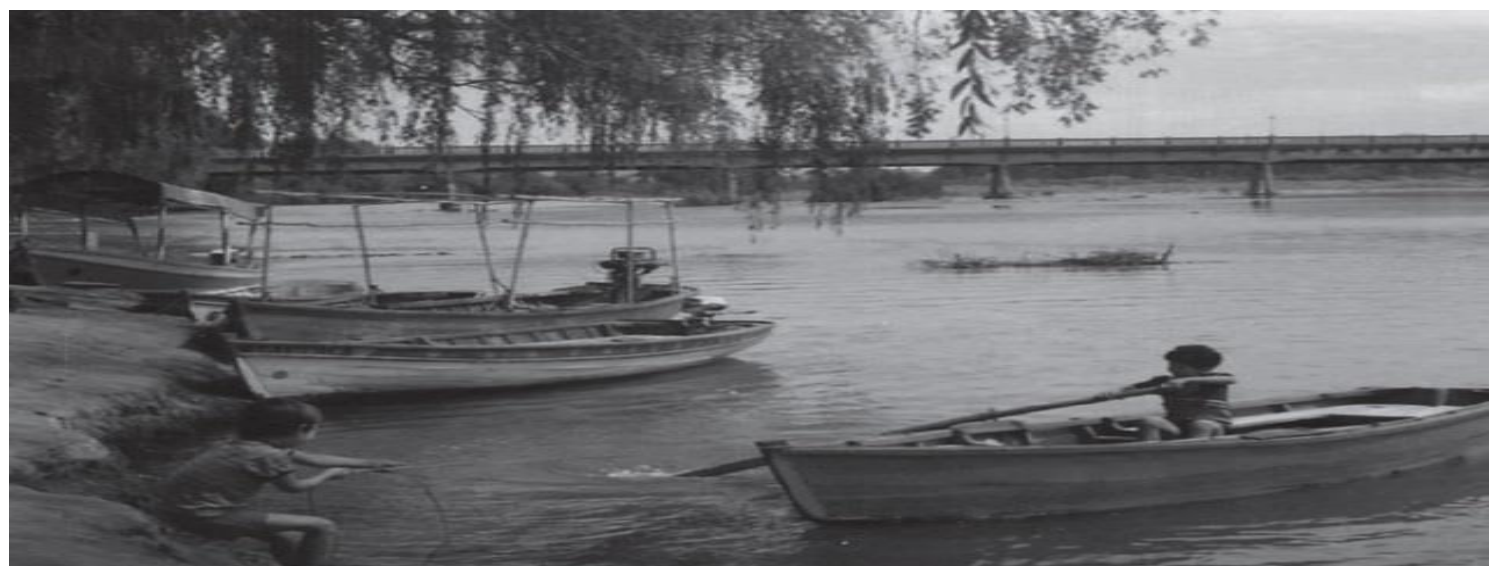

Fotografía niños en el río Claro. Autor C. Orellana. (imagen extraída de desde Agua y Patrimonio en la R. del Maule, 2015) 


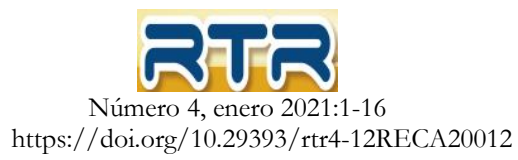

\section{Objetivos específicos:}

1. Incentivar el uso de los ríos como espacio público, a partir de su preservación y mantenimiento de sus aguas, destinando un número de funcionarios encargados de fiscalizar el buen uso de su ribera, para evitar la aparición de microbasurales y vertederos ilegales, entre otros, a través de una ordenanza municipal.

2. Generar un circuito de transporte fluvial que conecte a través del río Claro las comunas de Rio Claro, Talca y Maule, favoreciendo el trabajo sistémico entre municipios, a partir de la creación de una alianza estratégica de cooperación para fomentar el turismo de la provincia.

3. Dotar de botes nuevos a la futura asociación de barqueros que serán parte del eje fluvial río Claro.

4. Crear muelles en los ríos Piduco, Lircay y Claro, conectando distintos sectores de la ciudad a partir del transporte acuático, ya que actualmente esta infraestructura no existe.

5. Conformar una asociación de barqueros del eje fluvial río Claro, con el fin de formalizar este rubro, fomentando la cooperación entre sus integrantes y para establecer criterios de trabajos transversales.

6. Diseñar y construir en las riberas de los ríos Claro y Piduco, infraestructura para la instalación de locales comerciales.

7. Potenciar el comercio local, incentivando la instalación de negocios que favorezcan el comercio talquino, siendo parte de ello, una rebaja en el cobro de las patentes municipales.

8. Gestionar el aumento de contratación de personal, encargado de la limpieza y el mantenimiento exclusivo de los ríos Claro, Piduco y Lircay en la comuna de Talca.

\section{Potenciales problemas a enfrentar en el ámbito de la política pública}

Considerando que el proceso de implementación de la política pública podría verse comprometido o demorado por situaciones ajenas a su diseño, es que se indican potenciales problemas a enfrentar para esta.

A continuación, se presentan los siguientes problemas:

1. Demora en tramitación de fondos concursables para la implementación de la política pública.

2. Problemas derivados por mal estado del terreno en donde se ubicarán muelles en ríos Claro, Piduco y Lircay.

3. Falta de conciencia por parte de la ciudadanía en la limpieza del borde de los ríos y sus aguas.

4. Baja participación de la ciudadanía en relación a diagnóstico sobre revitalización del eje fluvial río Claro.

\section{Indicadores de la política pública}

Los indicadores de la política pública para la revitalización del eje fluvial río Claro, permitirán medir el cumplimiento de los objetivos propuestos y con ello, conocer el alcance e impacto que tiene esta política en la comuna de Talca, Río Claro y Maule. A continuación, se presenta el siguiente indicador principal:

1.Aplicación de encuesta de satisfacción ciudadana, que mida el grado de aceptación de los nuevos espacios públicos que son parte de la política pública del eje fluvial Río Claro. Siendo considerado positivo un resultado superior a $75 \%$ de aceptación por parte de la comunidad.

2. Disponibilidad y capacidad hotelera de la comuna de Talca, con un aumento anual de entre un $2 \%$ a un 7\% (Promedio mensual tasa de ocupación de un 37,9\% durante 2019. Fuente: Encuesta de alojamiento turístico INE).

\section{Indicadores complementarios política pública}

A partir de la medición anterior, se proponen indicadores complementarios, los cuales son: 
1. Crear un $100 \%$ de muelles para la navegación de los ríos Claro, Piduco y Lircay en un periodo de 3 años, conectando distintos sectores de la ciudad a partir del transporte acuático, ya que actualmente esta infraestructura no existe.

2. Establecer que la infraestructura para la instalación de locales comerciales, no sobrepase el 10\% del espacio físico de los parques aledaños a los ríos (Balneario río Claro y Parque Costanera).

3. Renovar el 100\% de los actuales botes turísticos de la ribera del río Claro a partir de la postulación a FNDR.

4. Gestionar el aumento de contratación de personal, de la empresa OHL Servicios Ingesan S.A, que desde el 2019 ofrece este servicio a la municipalidad. Desde las actuales 64 personas, pasando a un numero de 84 (aumento de un 23,81\% respecto a la contratación original).

5. Crear el 100\% de una asociación de barqueros del eje fluvial río Claro.

6. Establecer una rebaja de un $25 \%$ en el valor de las patentes municipales, para fomentar el comercio formal en los parques aledaños a las riberas de los ríos. En el caso del balneario Río Claro, aumentando el número de los actuales 7 locales comerciales a 14, es decir generar un aumento de un $100 \%$. Para el parque costanera, se espera instalar un número de 14 locales, lo que correspondería al $100 \%$ de comercio, ya que actualmente no existen servicios en este espacio público. Lo anterior en un periodo de 3 años.

7. Posicionar a la ciudad de Talca como un importante centro turístico regional, aumentando las agencias de turismo físico superior a 1 como es actualmente (Fuente: SERNATUR, 2019).

8. Reactivar la industria del turismo, generando fuentes de trabajo asociadas y aumentando el número de prestadores de servicios turísticos superior a 38 (Fuente: SERNATUR, 2019).

A partir de los objetivos específicos de la política pública, se propone lograr en un período de tres años instaurar un circuito acuático que conecte los ríos que desembocan en el eje fluvial río Claro. Además, en este período de tiempo, se busca consolidar el comercio formal en la zona y con ello, reactivar la economía del turismo en la ciudad de Talca.

A continuación, se presenta carta Gantt Para con la calendarización de actividades:

\begin{tabular}{|l|c|c|c|}
\hline \multicolumn{1}{|c|}{ Calendario fondos } & Primer año & Segundo año & Tercer año \\
\hline $\begin{array}{l}\text { Postulación } \\
\text { concursables para implementar } \\
\text { la política pública. }\end{array}$ & $\mathrm{X}$ & \\
\hline $\begin{array}{l}\text { Diseño y construcción de } \\
\text { muelles para red fluvial en ríos }\end{array}$ & $\mathrm{X}$ & $\mathrm{X}$ & \\
$\begin{array}{l}\text { Piduco, Lircay y Claro en Talca. } \\
\text { También aplica para los futuros } \\
\text { muelles en las comunas de }\end{array}$ & & & \\
Maule y Río Claro. & & & \\
\hline Limpiezas bordes de ríos. & $\mathrm{X}$ & $\mathrm{X}$ & \\
\hline $\begin{array}{l}\text { Proyectar en el eje fluvial rio } \\
\text { Claro y Piduco, la delimitación } \\
\text { de comercio local de carácter } \\
\text { formal }\end{array}$ & $\mathrm{X}$ & & \\
\hline $\begin{array}{l}\text { Gestionar tramitación e } \\
\text { instalación de comercio en el } \\
\text { balneario río Claro y Parque }\end{array}$ & & $\mathrm{X}$ & \\
Costanera. & & & $\mathrm{X}$ \\
\hline
\end{tabular}




\begin{tabular}{|l|l|l|l|}
\hline $\begin{array}{l}\text { Creación de asociación de } \\
\text { transporte fluvial para los ríos } \\
\text { Claro, Piduco y Lircay. }\end{array}$ & & & \\
\hline $\begin{array}{l}\text { Puesta en marcha circuito } \\
\text { acuático en los ríos y apertura } \\
\text { comercio en parque. También } \\
\text { se realizará entrega de botes } \\
\text { nuevos. }\end{array}$ & & & $\mathrm{X}$ \\
\hline $\begin{array}{l}\text { Contratación de personal para } \\
\text { limpieza y preservación de los } \\
\text { ríos y parques. }\end{array}$ & $\mathrm{X}$ & & \\
\hline
\end{tabular}

\section{Actores involucrados en la política pública}

Para la implementación de la política pública en el eje fluvial río Claro, es importante considerar la participación de actores que son claves dentro de la sociedad. Estos cumplen en algunos casos, el rol de usuarios de los diferentes espacios públicos, también son parte de la revitalización del espacio público, ya sea como parte del comercio o también como los agentes desde donde se va a ejecutar la intervención, como pueden ser diferentes organismos de gobierno. Dicho lo anterior, a continuación, se presentan los actores involucrados en la política pública:

1. Alcalde Ilustre Municipalidad de Talca

2. SECPLAN

3. $\mathrm{COSOC}$

4. Unidad de Medio Ambiente de Talca (municipio)

5. Ciudadanos de Talca, Río Claro y Maule

6. Ministerio de Vivienda y Urbanismo

7. Ministerio de Desarrollo Social

8. Ministerio de Economía

9. Gobierno Regional del Maule

10. Servicio y turismo municipal (es parte de la cámara de comercio de Talca)

11. Asociación de barqueros y transporte fluvial de la rivera del Río Claro en Talca

12.- Asociación de microempresarios del balneario Río Claro y Parque Costanera

13.- Junta directiva con los diferentes estamentos para la administración del parque (gobierno comunal, barqueros, comerciantes, ciudadanía)

14. OHL Servicios Ingesan S.A. (Empresa de limpieza)

15. Dirección de Obras Hidráulicas.

16. CORFO (Para dotar a las nuevas pymes de recursos)

\section{Ejemplo de ciudades fluviales}

Para este estudio, se consideran ejemplos internacionales y nacionales de ciudades donde se aplicaron políticas públicas asociadas a la recuperación de bordes de ríos, y donde, se realizó revitalización social y comercial de su rivera a favor de los(as) ciudadanos(as). 


\section{Modelos internacionales}

Dentro de los modelos internacionales para revitalizar un centro urbano en base a su potencial fluvial, se encuentra el Parque de España, en la ciudad de Rosario Argentina. Este proyecto se caracterizó por el dinamismo que se le intento otorgar a la ciudad a través de la renovación del frente fluvial de Rosario, potenciando el rio Paraná, principal fuente hídrica de la zona.

En este proyecto, se intentó reflejar las nuevas ideas de valoración del patrimonio cultural y natural, no obstante, debieron sortear dientes dificultades propias de la construcción de las ciudades contemporáneas. Sobre esta temática, Galimberti \& Rosado (2013) plantean que: "Posteriormente, la dificultad para la conducción y seguimiento del proyecto desde España, la falta de fondos para el financiamiento, los inconvenientes en la gestión del traspaso definitivo de la titularidad de los terrenos, y la incorporación del proyecto al Programa de festejos del V Centenario del Descubrimiento de América; ocasionan que el anteproyecto tome un rumbo distinto, con modificaciones respecto al programa inicial (Galimberti \& Rosado 2013, p. 12)

La zona ha tenido durante su historia una importante tradición portuaria que se remonta desde finales del siglo XIX y que posiciono a Rosario como una importante ciudad comercial, sin embargo, con el paso de los años y las diferentes crisis económicas, la ciudad dejo de tener la relevancia que poseía. No obstante, en la década de los treinta se plantea la necesidad de volver a vincular el río con la ciudadanía.

Para lo mencionado anteriormente, se recurrió al aumento de espacios verdes para la ciudad, así como también a la identificación de los elementos históricos relevantes para la localidad, de manera de respetar la memoria colectiva del lugar, siendo la valoración del patrimonio, el eje fundamental de este proyecto. Para esto se recurrió a la restauración de antiguos galpones ferroviarios que se utilizaron para la instalación de bares, restaurantes, alojamientos entre otros. Finalmente se puede concluir que este es un proyecto que refleja los resultados positivos de incluir elementos históricos y patrimoniales, aprovechando a su vez las ventajas en este caso de la morfología de la zona. Por otra parte, la buena gestión y participación también de las comunidades.

Otra intervención internacional es la del río Magdalena en la ciudad de Barranquilla Colombia. El proyecto Gran Malecón pretende resurgir y potenciar las riberas de este río que durante muchos años se mantuvo en el abandono.

Con una extensión de 1.500 kilómetros de largo, este afluente baja por la cordillera de los Andes hasta encontrarse con el mar de esta zona del caribe colombiano. Paralelo a este, se encuentra la ruta 40, por lo que el sector comprendido entre ambos espacios se ha utilizado como zona industrial y de vertederos lo que se busca revertir a través de esta inversión. Para lo mencionado anteriormente el proyecto busca utilizar casi en su totalidad el borde del de río, que consta de áreas verdes, plazas, ciclovías, senderos peatonales y construcciones urbanas, en conjunto con la construcción de una gran avenida de doble sentido con cableado subterráneo para su luminaria. Es por este motivo que el proyecto cuenta con una gran inversión, la que ha sido valorada incluso internacionalmente.

Dividido en cuatro etapas de construcción y un presupuesto de 450 mil millones de pesos colombianos (USD 159,7 millones), el primer tramo del Gran Malecón se inauguró en julio de 2017 y según cifras de la propia alcaldía, ya superó el millón de visitantes (...) El trabajo de estas primeras etapas le valió el Premio a la Excelencia Inmobiliaria en 2017, galardón otorgado por la Federación Internacional de Profesiones Inmobiliarias (FIABCI). (Valencia, 2018) 


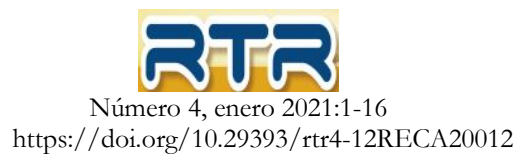

A través de este proyecto se consiguió que la ciudad de Barranquilla sea un referente tanto de crecimiento como del buen aprovechamiento y transformación de los espacios públicos, potenciando de esta forma el emprendimiento y dinamismo del cual alguna vez gozo esta región.

Finalmente, esta experiencia internacional nos puede orientar asimismo en otros desafíos que también se relacionan con el resurgir de estos espacios urbanos y tiene que ver con la descontaminación de los cauces, que producto de diferentes factores no cuentan con las condiciones de salubridad requerida para fomentar su uso.

Dentro de los factores más comunes que determinan el deterioro y la contaminación de las fuentes hídricas (principalmente en los sectores urbanos) encontramos precisamente el hombre. Es por este motivo que históricamente los ríos incluso más famosos han sido víctimas del fuerte crecimiento industrial de las ciudades y la poca conciencia de este impacto hacia el medio ambiente, por lo cual en la actualidad ciudades como Londres han debido responsabilizarse y hacer frente a esta situación a través de la generación de proyectos que apunten a descontaminar.

Un ejemplo sumamente representativo es el río Támesis, el cual data de una larga historia de contaminación de sus aguas que incluso llegaron a ser considerada no potables hacia el año 1610, no obstante, a pesar de que se intentaron tomar medidas al respecto, estas fueron poco significativas hasta en la década de los 70 aproximadamente, donde se realizaron nuevas acciones para descontaminar y revitalizar el sector.

Para lograr este objetivo, se invirtió en plantas de tratamiento de aguas residuales e incineradores de sedimentos procedentes del tratamiento de agua, generando energía para las mismas estaciones. Sin embargo, en la actualidad aún existen desafíos que superar, como lo es el plástico, producto de la acción humana que tiene gran repercusión en la flora y fauna que rodean este afluente.

La campaña por un Támesis más limpio fue lanzada en septiembre de 2015 para combatir la basura plástica. Es una batalla difícil porque hay demasiadas fuentes del problema. Pedazos pequeños de plástico, como los palitos de los hisopos y microcuentas de los exfoliantes faciales y la pasta dental, generalmente terminan en inodoros y lavamanos. Pueden pasar los filtros y pantallas de las plantas de tratamiento de aguas residuales y tardan años en descomponerse. (Hardach, 2015)

Actualmente el Támesis aún enfrenta los desafíos de superar la contaminación derivada de la acción humana, en un río que atraviesa el sector urbano más importante de Inglaterra, por lo que es importante rescatar de este ejemplo, que estos procesos son complejos y requieren de inversión, tiempo y sobre todo la conciencia de los habitantes.

\section{Modelos nacionales}

Otro ejemplo, pero esta vez nacional, se encuentra en la comuna de Penco donde se ha potenciado el eje turístico marino y fluvial de la zona con resultados bien acogidos por la comunidad.

Parte del proyecto consiste en la incorporación de réplicas de góndolas venecianas (construidas por artesanos de la zona) y opera a bordo, que transitan por el estero navegable de la zona como una manera de rescatar los orígenes de la comuna, que en sus inicios fue cuna de familias italianas. Por otra parte, también se aprovecha el recurso acuático estableciendo un circuito de navegación por la bahía de la comuna, para lo cual se ha incorporado al sindicato de pescadores de Lirquén que se hizo cargo del servicio.

Otro punto importante es la concientización de la relevancia de cuidar y mantener el buen estado de las playas y el sector.

Finalmente es necesario mencionar que el proyecto de la comuna de Penco impulso actividades acuáticas como manera de potenciar el turismo de la bahía. Aunque este proyecto fluvial se presenta a una escala menor al de otros ejemplos internacionales, existen factores en común como la 


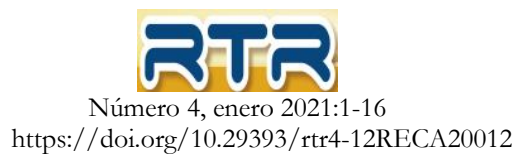

incorporación de la identidad de la zona, la participación de las comunidades y también la buena gestión y proyección de quienes impulsan estos proyectos.

Otro caso reconocido a nivel nacional, es la transformación del eje fluvial de la ciudad de Valdivia, el cual ha vivido una transformación desde el apogeo industrial que experimento la zona durante el siglo XVII y XVIII, con la generación de talleres de manufacturas de origen agrario, que derivó en que la economía de este periodo se basara en un "mercado de agrocultivo" y que al desaparecer debió enfrentar a la comunidad a un conflicto en el desarrollo territorial, que se pudo superar gracias a diferentes factores. Uno de ellos fue comprender que el río es un componente fundamental de la ciudad y que construye paisaje.

Por otra parte, se comprendió que el rescate cultural de este periodo, sería fundamental para preservar la identidad y promover de esta manera la nueva ciudad, incorporando su tradición histórica fluvial, con las necesidades actuales de la comunidad. Sobre esta situación, Saelzer \& Urbina (2015) plantean lo siguiente:

Para replantear el espacio fluvial, se cuenta con la identificación de al menos la silueta colonial, la de una etapa y estado finicolonial e industrial de la ciudad-puerto, y la transformación del recuerdo en un fenómeno inmaterial. Es decir, la recolonización silvestre, la edificación tanto inmobiliaria como vial de los bordes, y las interpretaciones históricas como parte del desarrollo del paisaje urbano en la esfera cultural. (Saelzer \& Urbina, 2015, pág. 99)

Es así como se crea el Sistema Interconectado de Transporte Fluvial en Valdivia, el cual tiene por objetivo incorporar las necesidades de la comunidad, como la conectividad de la ciudad y sus diferentes barrios, generación de fuentes de trabajo como lo es la oferta de recorridos turísticos por el rio, el alojamiento, la inversión de empresas y la descongestión del flujo vehicular de la ciudad. Todo esto complementado con la revitalización de su historia, mezclado con la generación de una imagen de ciudad moderna, que incluye en ella, el desarrollo sustentable.

Todo lo anterior devolvió al río su importancia y lo transformo en el eje más importante de desarrollo de la zona, posicionando a esta ciudad como la principal ciudad fluvial de Chile.

Thayer (2011) señala que "el desarrollo regional implica su acción no solo en la definición de los objetivos del desarrollo, sino también en la definición de las estrategias que posibilitarán llegar a esos objetivos" (pág. 269). Dicho esto, y para concretar los objetivos de la política pública, se presentan sus mecanismos de financiamiento orientados para la revitalización del eje fluvial río Claro.

De acuerdo a lo anterior, se realizará una postulación a diferentes mecanismos de financiamiento concursables:

1. Se requiere Postulación a recursos del FNDR a través del Gobierno Regional del Maule, para la ejecución de la política pública de revitalización del eje fluvial río Claro, considerando que se trata de un proyecto intercomunal entre Talca, Río Claro y Maule. Este fondo asigna el 90\% de los recursos a comienzos del año presupuestario, y el 10\% restante se destina en igual proporción, a cubrir situaciones de emergencia y estímulos a la eficiencia. Por otra parte, cada comuna deberá presentar su propuesta de diseño y planificación pertinente en la Secretaría Comunal de Planificación referido a los objetivos de este plan de revitalización fluvial.

A continuación, se presentan las diferentes obras a realizar en estos espacios públicos, a través de FNDR:

A. Instalación de locales comerciales en balneario Río Claro y Parque Costanera, donde se proyecta la instalación de 14 locales en cada uno de estos parques. 
B. Construcción de un muelle en cada río de la comuna de Talca, destacando el Piduco (centro de la ciudad), Lircay (sector oriente) y Claro.

C. Construcción de un muelle en las comunas de Río Claro y Maule, las cuales conectan con el eje fluvial Río Claro en la ciudad de Talca.

D. Dotación de botes para la navegación de circuito acuático, para las tres comunas involucradas.

E. Licitación de empresa particular de limpieza para el cuidado y mantención de los parques y riveras de ríos.

Aunque no forma parte del proyecto de postulación al Fondo Nacional de Desarrollo Regional, cabe destacar que cada municipalidad involucrada establecerá como compromiso desempeñar las siguientes tareas:

A. En la ciudad de Talca, se realizará una modificación a su presupuesto anual en patentes y tasas por derechos, que el año 2020 asciende a $\$ 8.480 .450$, con el fin de rebajar el cobro de las patentes municipales a las personas que deseen instalarse en los parques fluviales.

B. Ordenanza municipal en las comunas involucradas, que apunte a fiscalizar y resguardar los ríos como un bien público, evitando el aumento de vertederos ilegales y contaminación de las aguas.

En el caso de surgir complicaciones en la postulación de Fondo Nacional de Desarrollo Regional para la política pública a implementar, se sugieren las siguientes alternativas complementarias para su financiamiento:

A. Instalación de comercio en parque rio Claro y Costanera: Se construirá infraestructura para la instalación de 14 locales comerciales (comida, artesanías, etc.) por parque (28 en total).

Financiamiento de la operación: Postulación a Fondo Regional de Inversión Local (FRIL), indicando que este fondo entrega un máximo de 90 millones (2000 UTM) por proyecto y se postula a través GORE.

B. Construcción de muelles en Talca, Maule y Río Claro, que conecte dichas comunas a través del río Claro. Complementario a ello, también se incorporarán muelles en los ríos Piduco y Lircay en la ciudad de Talca (un muelle en cada río).

Financiamiento de la operación: Postulación a Programa Mejoramiento Urbano (PMU) que entrega un máximo 60 millones y donde cada municipio debe postular por separado.

C. Adquisición de botes para la naciente asociación de barqueros.

Forma de financiamiento: Postulación por medio del Gobierno Regional y Ministerio de Hacienda a Circular 33, que son los gastos por concepto de adquisición de equipos empleados para transportar personas y objetos.

\section{Conclusión}

A partir de este proyecto de revitalización para el eje fluvial río Claro en la ciudad de Talca, incorporando además a las comunas de Río Claro y Maule, se concluye que se buscó como foco central la recuperación de los ríos de la ciudad, atrayendo comercio, diferentes servicios y actividades ciudadanas a sus riberas. Para ello, se tuvo que trabajar desde una planificación rigurosa de actividades que permitieran lograr esta política pública, ya sea postulando a las distintas formas de financiamiento con el fin de crear por ejemplo un transporte acuático que pase por los ríos Piduco (centro de la ciudad) 
y Lircay (sector oriente), buscando llegar al río Claro el cual conectará además con las comunas de Río Claro al norte de Talca y con Maule en el sur, reactivando la navegación de los ríos y que tiene sus orígenes en el siglo XIX con los antiguos faluchos maulinos del río Maule. En otras palabras, se buscó retomar una actividad histórica para la región del Maule.

Además, cabe mencionar que esta política pública, también persigue transformar a este eje fluvial en uno de los principales centros turísticos de la región, esto a partir del uso y navegación de los ríos y la instalación de comercio en los parques aledaños como son Costanera y Balneario río Claro. Esto sin duda, posicionará a la zona como un importante destino turístico, fomentando esta industria y ayudando a la economía local de las comunas por donde se integrará esta red acuática.

A partir de lo concluido en este trabajo que buscó la revitalización de eje fluvial río Claro. Dicho esto, se sugieren las siguientes recomendaciones hacia quienes se interesen en profundizar sobre modelos de ciudades fluviales:

1. Generar identidad en la formulación de proyectos, en base a la tradición e historia de la zona en que se llevará a cabo la política pública, considerando a las pequeñas localidades aledañas al río Claro.

2. Se considera muy necesario la realización de consultas ciudadanas en la formulación de proyectos de alto impacto para la comunidad.

3. Generar un mayor vínculo entre los diferentes actores que inciden en la política pública, a partir de una sistematización del trabajo y la generación de un vínculo más estrecho entre los mismos.

4. Hacer hincapié en la necesidad de establecer un equilibrio entre la tradición de las localidades y políticas públicas orientada a los requerimientos de la sociedad actual, como lo son la conciencia ecológica y el cuidado del medio ambiente.

5. Potenciar los datos y elementos cuantitativos para la recolección de estos, para así incorporarlos en la industria del turismo con la finalidad de generar información que permita medir de forma más clara este rubro y así poder potenciarlo.

\section{Bibliografía}

Baltanares, Claudi y Figueroa, Felipe (2018). Las transformaciones del Río Claro. En: https://laderasur.com/articulo/un-impresionante-registro-de-las-transformaciones-a-lo-largo-del-rioclaro/p8/ visitado 12 de noviembre 2020.

Cal, P. d. (2002). Ríos y ciudades: Aportaciones para la recuperación de los ríos y riberas de Zaragoza. Zaragoza: Universidad de Zaragoza.

Dirección General de Aguas. (2004). Diagnóstico y de los cursos y cuerpos de agua según objetivos de calidad: Cuenca del Río Maule.

Galimberti, C., \& Rosado, J. (2013). Parque España: un proyecto para la reconversión del frente fluvial de Rosario. Portus, 49.

Hardach, S. (2 de Diciembre de 2015). BBC Newss. Obtenido de https://www.bbc.com/mundo/noticias/2015/12/151120_vert_earth_rio_tamesis_yv

INE. (2017). www.ine.cl. Recuperado el 03 de noviembre de 2020, de www.ine.cl: http:/ / resultados.censo2017.cl/Region?R=R07

Judd, D. R. (2003). El turismo urbano y la geografía de la ciudad. (Eure, Ed.) Scielo, XXIX(87), 51-62.

Maino, V. (1996). La navegación del río Maule, una vía de conexión con el exterior 1794-1898. Talca: Editorial Universidad de Talca.

Quintero, M. C. (2019). Ciudades sostenibles. Obtenido de Ciudades sostenibles: https://blogs.iadb.org/ciudades-sostenibles/es/lac-cities-challenge-proyectos-innovadoresregeneracion-urbana-desarrollo-economico-local/

Saelzer, G., \& Urbina, S. (2015). URBANISMO FLUVIAL EN EL APOGEO INDUSTRIAL DE VALDIVIA: DESAPARICIÓN Y RECUPERACIÓN (ca. 1850-2012). 99. 
Sánchez, R. (2012). Thalcamo: Pueblo de indios del Maule. Talca: Museo O'Higginiano y de Bellas Artes de Talca.

Simón, I., \& Sánchez, R. (2015). Agua y patrimonio en la Región del Maule (1850-1930): una mirada desde la historia. Talca: Consejo Regional de la Cultura y las Artes. Región del Maule.

Thayer, L. (2011). Descentralización y desarrollo regional en Chile. Una mirada desde la sociedad. Revista de la Universidad Bolivariana, 10(30), 267-287.

Valencia, N. (15 de Mayo de 2018). Plataforma Arquitectura. Obtenido de https://www.plataformaarquitectura.cl/cl/894537/gran-malecon-del-rio-magdalena-elproyecto-que-le-esta-cambiando-la-cara-a-barranquilla

Valenzuela, E. (2017). Descentralización 2.0 Construyendo la gobernanza regional que Chile necesita: un desafío país. En E. F. Descentralizado. Temuco: Ediciones Universidad de la Frontera.

Valenzuela, Esteban. (2017). La esquiva y nunca implementada democratización regional en Chile. En Cuadernos de Política Exterior Argentina (págs. 71-82). Rosario: CERIR. 